\title{
Pottery Community Characteristics Toward A Learning Community In Thai Context ${ }^{1}$
}

Suchada Namjaidee, Khon Kaen University, Thailand Lampang Manmart, Khon Kaen University, Thailand Yaowalak Apichatwallop, Khon Kaen University, Thailand Peerasit Kamnuansilpa, Khon Kaen University, Thailand

\begin{abstract}
This article is an analysis of community characteristics toward learning community in Thai context in three aspects: 1) characteristics of community people, 2) community environment consisting of existing knowledge and natural resources, and 3) learning processes. It is a qualitative research study for which the researcher collected data by participant observations and in-depth interviews. The researcher had been in the community and participated in community activities for ten months. The tools employed in this research comprised of interviews, observations, and field records. Individuals interviewed were official and non-official leaders and community people. It was found, by this research, that the pottery community has evolved and developed toward a learning community over time which can be seen from people in the present community consisting of both natives, entrepreneurs and business owners, and community leaders. Community environments that support or lead to learning were pottery-making knowledge and clay knowledge, including learning resources, such as knowledgeable individuals, natural environment, factories, jar houses, kilns, and community shops scattered all over the community. Besides, the community has its own learning center with local traditional curriculum involving pottery making for new generations to learn and maintain such knowledge and expertise. Regarding learning processes, community people began to learn the craft of making pottery from outsiders and transferred it to their family members, from one generation to another. In the meantime, with outsider visits and purchases of pottery products, further learning exchanges took place, no longer confined to family members, but expanding to include learning with people in the community, academics, experts, and designers who came in contact with the community. During these periods, there were further transfers of knowledge and skills to community people and close assistants called "Luuksit", or students. Moreover, when the commercialization of pottery products materialized, community people had a chance to learn and interact with outsiders who came in as teachers and training experts, study tours outside the community, suggestions from customers, and exchange of ideas between the community, resulting in transferring knowledge and skills to wider audiences. Moreover, the community people learned from problems arising from the production process and opened up themselves to new knowledge from various media.
\end{abstract}

Keywords: learning community

\section{INTRODUCTION}

lobalization has created networks and interconnections of information and communications among various countries of the world with no boundary (Prong, 2005; Jirawat, 2005) and caused changes in economies, especially economies that are seeking to compete as knowledge-based economies, or driven by knowledge. In the early $21^{\text {st }}$ century, several countries of the world modified and adjusted investment bases for knowledge-based economy and industries, placing more importance on the creation of knowledge bases and organizational talents to

\footnotetext{
${ }^{1}$ Revised from the Doctor of Philosophy Thesis in Development Science, Graduate School, Khon Kaen University. The thesis title is Development Processes towards a Learning Community.
} 
have a competitive edge over other countries, which is an important part of developing world community into a learning community with no exception. Thailand has been affected by such changes in the world community, resulting in Thailand's paying more attention on developing knowledge-based economy and human resources into a wisdom and learning society (Bordin, 2001). This can be seen from the $9^{\text {th }}$ and $10^{\text {th }}$ National Economic and Social Development Plans, including Government Policy Framework for Information Technology (2001-2010). The Secretariat of the Committee on National Information Technology (2002), appointed by the government, has determined approaches to developing the country into a wisdom and learning society, emphasizing the development of human resources, communities, and environment in a balanced fashion by using information technology as a tool to accelerate the development according to the $9^{\text {th }}$ and $10^{\text {th }}$ National Economic and Social Development Plans. The policy framework for information technology clearly explained the definitions of a wisdom and learning community that accepts learning culture, utilizes knowledge as the basis for development, and acknowledges that knowledge is a social asset. Therefore, to promote production of goods and services, or community enterprises, there must be a transfer of knowledge to the community on a wider scale for the community to benefit. There must also be a stimulation of various levels of labor in the community, promotion of the community to be fully aware of importance of blending the existing knowledge with the new knowledge from external sources to strengthen economic systems and the ability of the community and the country to compete $\left(9^{\text {th }}\right.$ National Economic and Social Development Plan, 2002-2006; $10^{\text {th }}$ National Economic and Social Development Plan, 2007-2011; Secretariat of the Committee on National Information Technology, 2002). From such currents of globalization, contemporary economic and social development has forced Thailand to develop itself into a wisdom and learning society. This led to a research question of "Which approach would it be in developing a learning community in the different contexts of society?"

However, when the analysis was conducted, it was found that society comprises of human beings, community, and environment. As laid down by the National Economic and Social Development Plans, it can be said that community development is considered a basic component, important for developing society into a wisdom and learning society within the framework devised in the two National and Economic Development Plans, which have defined a "learning community" as a community that encourages and supports creation, transfer, and utilization of knowledge, including the ability to manage natural resources and knowledge as local wisdom through mechanisms of networks of community cooperation, aiming to strengthen community, achieve self-reliance and self-sufficiency, and reciprocal hospitality in the community. Evidently, the major components of a learning society include human beings, community environment that includes body of knowledge, natural resources, community learning sources, and the process of knowledge transfer $\left(9^{\text {th }}\right.$ National Economic and Social Development Plan, 2002-2006; $10^{\text {th }}$ National Economic and Social Development Plan, 2007-2011; Secretariat of the Committee on National Information Technology, 2002).

Approaches to developing a community into a learning one are varied, covering the creation of a new community, such as academic, research, and learning communities. These communities may use information technology as a tool to communicate or transfer a body of knowledge among themselves (Secretariat of The Committee on National Information Technology, 2002). Nevertheless, development of a community from social development viewpoints is not the development or creation of a new community, but in society, it is the development of the original society, which refers to a unique area with land, human beings, occupations, culture, economy, local knowledge, and a long history of learning culture (Parichart Walaisathien, et al., 2003). These communities have evolved and developed in the environmental context and have changed over long periods of time; some communities that could not adapt to the social changes and globalization impacts died out (Marquardt, 1996), while some communities could not only develop and adapt to new environment and changes, but also bring local wisdom and knowledge into use for economic purposes. In the meantime, they are able to transfer their body of knowledge from one generation to another within the community, and likewise are able to create a learning society. Thus, in studying approaches to developing a community into a learning society, it is necessary to study it from the original existing community that could develop itself into a self-reliant community, could bring local wisdom into use for daily life benefits and welfare of the people in the community, and at the same time, could preserve and protect the body of knowledge and local wisdom for the next generations to come in an apparently clear manner.

In order to study approaches to developing a community into a learning one, a conceptual framework has been developed to understand lessons learned from existing communities that have evolved and developed by 
themselves over a long period of time and have been accepted at a certain level as a community that is able to transfer a body of local wisdom and knowledge for the benefit of people living in that community. At the same time, it is a community that is able to maintain and extend that local intellectual heritage. The present study chose a community in Dan Kwien Subdistrict, Chokchai District, Nakhon Ratchasima Province (Thailand), with the main purpose of analyzing and seeking the characteristics of a learning community in Thai context from the development and evolution of Dan Kwien community.

\section{RESEARCH FRAMEWORK}

In the study of the characteristics of a learning community in Thai context, the researcher has developed the theoretical framework by applying theories and concepts related to a learning organization, as in Senge (1990), Markquardt (1996) and Garvin (1993).

Although all these theories and concepts are used to explain the learning characteristics of a formal organization, many research studies showed that they could also be applied to the learning characteristics of a nonformal organization. On the basis of these three theories, it can be seen that the three factors most salient for the development into a learning community are people in the community, community environment, and the process to transfer bodies of knowledge in the community.

\section{People in the Community}

People or residents are important factors in a learning community. Senge (1990) states that people in a learning community must possess five major characteristics:

1. Personal mastery

2. Mental models

3. Shared vision

4. Team learning

5. System thinking

Based on these theories, Seri Pongpit has applied and adapted Senge's (1990) concept for developing a learning community in his Study of Reflective Village and Vision for Development, the story about Uncle Kieng Kongkaew who tried so hard to develop his fruit orchard into neo-agriculture consisting of a diversity of plants, fruit trees, vegetables, and herbs, which will make farmers self-sufficient. Uncle Kieng's agricultural orchard has now become a learning community and Uncle Kieng is willing to transfer his knowledge to benefit others and share their learning. Therefore, in a learning community, people must be eager to learn and to create an atmosphere for learning according to their needs and aptitudes; they must be able to learn independently from problems occurring in their community and solve those problems, which will lead to creation of new bodies of knowledge and ability to work with others on a hospitable basis.

\section{Community Environment}

The environment conducive to learning comprises:

1. community knowledge, including tacit knowledge of specific fields that can be interchanged, including ways of life, milieus, and society, which are cultural knowledge, social base, and resources of the community

2. learning resources, such as institutions, buildings, shops, libraries, monasteries, or resource persons, such as traditional teachers or community leaders

Learning resources provide ways that formal and informal learning can take place. Marquardt (1996) stresses on creating an atmosphere for both individualized and group learning, educating people in an organization in an analytical system, thinking to better understand the situation and allowing everyone to assist the organization by learning from successes and failures of the organization which will, in turn, make everyone aware of changes and 
able to adjust themselves in a timely way. This concept was reflected in the research by Supatra Chatbunchachai (n.d.) on a learning community of Kham Pla Lai Village, Ubonrat District, Khon Kaen Province, which showed that learning atmosphere and environment:

- $\quad$ come from community leaders who can motivate people to participate by offering their opinions for solving problems together

- $\quad$ encourage the application of local wisdom to add values

- $\quad$ support study tour to learn from other communities and apply knowledge for the community benefits

- $\quad$ encourage people to transfer their knowledge among themselves

Moreover, the community leaders should develop the community into a learning resource and cultural cooperation center for everyone to help and share, making them realize the importance of lifelong learning, living close to and protecting nature, thereby building common consensus for conserving and sustaining natural resources. In short, this research pointed to the fact that a learning community depends heavily on learning atmosphere created and motivated by community leaders.

\section{Learning Process or Knowledge Transfer}

The learning process of people in the community is the heart of a learning community in the sense that it generates more learning and more transfer of knowledge. The learning process starts with daily life activities and, in the process of knowledge transfer, important components include resource persons such as community leaders, traditional teachers, and community people. However, Garvin (1993) explains that the transfer of knowledge and experience may result from learning about successes and failures in the past, from lessons of solving the problems, or from experimenting new concepts. Transfer of knowledge in a learning community may take place in the form of person-to-person, community-to-community, community-to-outside, or outside-to-community contexts. Besides, the process of knowledge transfer may depend on real practical knowledge, formal and informal education, or summaries of lessons learned from exchange ideas with other people in the community. Methods of learning may include direct learning with specialists or experts, creation of a knowledge transfer center in the community, or bringing in knowledge from the outside.

However, learning of people in the community mostly comes from an existing body of knowledge or from solving the problems faced; for example, the study by Phra Maha Sutit Apakaro (Oboon) (n.d.) on Learning Innovation: People, Community, and Development, and the case study by Sinchai Boonart, which concluded that an environment of knowledge and innovation could be created for rice transplantation in Thailand. This can be brought about by learning from real situations and experience through systematic improvement and solutions until rice types can be developed into good quality and high yields.

Based on the study of theoretical research framework and its applications in various community research works, the researcher then determined the conceptual framework for studying the characteristics of a learning community in Dan Kwien Sub-District, Chokchai District, Nakhon Ratchasima Province, which is considered to have evolved over a long time and has been prominent in creating and applying local knowledge and wisdom in the following three aspects:

1. People: By studying people's characteristics in the process of learning, it is possible to foster the creation of knowledge and applications of knowledge for social benefits and self-development.

2. Environment: An environment that is conducive to learning consists of existing community knowledge, community learning resources, such as resource persons, appropriate venues, and natural resources.

3. Knowledge transfer process of people in the community is an in-depth study of the knowledge transferred from the community to community members, from the community to the outside, and from the outside to the community, with the main focus on a pottery community within the Thai context. 


\section{RESEARCH METHODOLOGY}

This is a qualitative research using participatory observation as the major tool for the inquiry. The researcher spent ten months establishing relations and participating in the community activities. Data had been carefully collected to accurately reflect the real situation in the study area of 16 communities of Dan Kwien Subdistrict, Chokchai District, Nakhon Ratchasima Province.

In collecting data, the researcher used observations and interviews with two types of important informants individuals and householders. Individuals consisted of 25 long-time senior residents of the community with whom a group interview was administered to collect the basic data on the community. The householders included community leaders, such as traditional teachers, Mayor, village chiefs, village head men, and 30 pottery-making households. With this group, in-depth interviews were conducted to collect data on the Dan Kwien pottery-making process. Additionally, the researcher used both non-participant observation and participant observation to study various aspects of the community ways of life. The researcher also examined the existing secondary data and related research reports to collect and analyze documents related to the history and transitional periods of the Dan Kwien community.

For validation, the researcher held a focus group meeting with 20 stakeholders consisting of development officers, traditional teachers, community leaders, school teachers in the community, and representatives of potterymaking households. Then, the researcher presented the analysis of data on the characteristics of a learning community in Dan Kwien sub-district. The collected data were classified by topics, analyzed, and compared to arrive at the conclusion. Next, the data were analyzed in the overall picture according to the theoretical framework. Finally, the research results were reported by descriptive essay.

\section{RESULTS OF THE STUDY}

\section{Dan Kwien Community Context}

Dan Kwien is an ancient community, 17 kilometers away from the city of Nakhon Ratchasima, along Highway No. 224, occupying an area of 24 square kilometers. It started well before 1922 as a small community near the bank of the Mool River. When the river flew past, it caused the formation of meanders and protrusive soil. The alluvial complex soil and buried soil later become natural resources rich in minerals and other valuable elements. This type of soil has unique features in that when it is used to make pottery, it shines brightly by its own nature and holds water very well (Institute of Arts and Culture, Rajabhat University Nakhon Ratchasima, 2001).

In the past, Dan Kwien community was an agrarian society, engaged in farming, vegetable gardening, and animal husbandry along the Mool River. The beginning of Dan Kwien pottery-making has not been clearly established. Available evidence showed that it might have started in 1918 when the 'Kha' people came to Korat from their original homeland along the Mekhong River near the city of Champasak. The Kha people were known to locals as Lao gypsies who came to work for wages annually (Local Knowledge and Wisdom Recording and Dissemination Project, Technical Assistance Center, Community Development Region 11, Nakhon Ratchasima, n.d.). Therefore, it was assumed that they came to work as masons for Buddhist temples and ordination halls. Their living shelters were called 'Takutkha' (now, a natural pond, east of Dan Kwien Temple). Because building temples and ordination halls took a long time to complete, Kha masons, at the same time, turned to making household utensils, such as jars, jugs, pots, and mortars, using clays from Takutkha, the place where they lived. Since clays from Takutkha were mixed with various minerals and elements, when they were kneaded and molded, they looked shiny, highly polished, and not easily breakable. They could also hold water very well. Local people began to realize the fact that Kha's potteries were beautiful and useful for daily use, so they took an interest in learning the arts and craftsmanship of pottery from the Kha people for household use.

Later on, in 1977, Chinese traders came on the scene and opened shops and groceries. They also acted as middlemen buying and selling potteries in the community. When roads and transportation were more convenient, more traders from outside came in and bought pottery from local makers to sell elsewhere, gradually leading to commercialization of pottery products. Pottery-makers then developed their products for marketing purposes. They 
built work places called 'Rong Hai', or 'Jar House', with their family members, cousins, and relatives as workers or producers. The Rong Hai were seen as a learning resource and a place for knowledge transfer in the community.

As education progressed, in 1957, lecturers or teachers from Northeastern Technical College visited and observed the making of pottery in Dan Kwien community. After that, they disseminated the information and publicized the pottery made in Dan Kwien to wider audiences outside the community. They also applied technical knowledge and knowledge of modern designs while learning and sharing with local potters, resulting in more beautiful and colorful products with new designs and added value. This led to the combination of old and new knowledge and transfer of knowledge within the community. At the same time, pottery-making became an occupation for local people. Some turned pottery-making into home-based businesses and transfered the knowledge to their family members and relatives so that they all could practice in the workplace called 'Rong Hai'.

Later, another important transition took place when Dan Kwien potteries and clays were bought to decorate the interior and exterior parts of the Ordination Hall of Sala Loy Temple in Nakhon Ratchasima, making the Hall more beautiful and famous. So, the Dan Kwien potteries became more popular with tourists and people from other places. Better transportation and traveling conveniences brought more tourists and general public to visit Dan Kwien community to buy pottery products which now became their main community products. Some families switched from farming to making pottery to sell.

The period from 1987 to the present was when Dan Kwien pottery entered the production system driven by industrial and capitalist forces; that is, pottery was made and marketed for sale in and outside the country, made to order and based on customers' demands. This served to introduce a new body of knowledge of production and designs to implement mass production. New technologies were applied to kilns and production tools. Some potterymaking families sent their children to study further at higher levels, both in Thailand and abroad, in the fields of contemporary art design, business management, and marketing. At present, there are many groups of people living in Dan Kwien community - natives and people from other places who migrated to work and earn a living in various types of jobs related to the pottery industry - as potters, decorators, carvers, carriers of kneading machines into kilns, burners, painters, repairers, designers, sales assistants, shop keepers, factory owners, etc. Dan Kwien nowadays has become a larger community with the pottery business as a brand name or symbol, having small, medium, and large kneading factories, sales shops, and learning resources for local people and the general public. Besides, Dan Kwien pottery has become a source of major income for local people, in particular, and for Korat or City of Nakhon Ratchasima, in general. It is also a unique feature of the community that when people talk about Dan Kwien, they have the image of a community that produces high quality, beautiful, and inexpensive pottery.

\section{POTTERY COMMUNITY AND LEARNING COMMUNITY}

Based on the study of Dan Kwien community, the researcher summarized the following results:

\section{People in Dan Kwien Community}

From the study, it was found that the people in Dan Kwien Community were divided into three groups: 1) native people, 2) pottery business owners or householders, and 3) community leaders. People in this community do not even think of destroying their unique Dan Kwien pottery village, but are interested in learning about it on account that pottery can benefit them and their families. However, each group of people has a different purpose in applying their knowledge of pottery making. Natives tend to produce pottery products for household use, exchange for items they do not have, and sell without focusing on profits. Thus, this group of people only learned to continue their traditional knowledge from the Kha tribe, not thinking of improving or developing the models or patterns of the products and other devices.

However, people in the community, during the period of development into a learning community, had the characteristics of learning by maintaining traditional knowledge of pottery making and acquiring new knowledge and skills from academics, art experts, and designers. They stressed on integrating their existing traditional knowledge and the modern one, which contributed to the result conveying the combination of those two. The results of their learning led to a variety of new, creative, and small models of their products, no longer focusing exclusively 
on household items, but also on vases and wall tiles. This group of people mainly produces pottery items for sale in and outside their community.

People in the community, during the period of developing their traditional knowledge into commercialization of their products, were focused on learning to further their traditional knowledge by opening themselves to new knowledge and skills from external sources through their leaders. These leaders, in turn, were involved in various activities conducive to learning and applying knowledge from outside experts and different media - including customers' suggestions - which were considered creative and innovative in pottery making through trials and errors before real application and transfer of such improved knowledge to the next generations. With their determined efforts and continuous improvement, their products became more elegant, delicate, and wellaccepted by both domestic and foreign customers.

Salient features of people in Dan Kwien Community are that they learn how to make pottery products in a natural way, without formal classroom teaching, but through real experience with knowledgeable specialists, experts, and potters as they wish. Inter-learning among community people, experts, and academics resulted in new models and patterns of their products. In addition, the problem-based learning approach of people in the community helped develop the designs and patterns of the pottery products. It also created a network of group learning in the community. This could be seen from the fact that people in the community were always invited to participate in - or learn from - those pottery households who succeeded in developing their products so that they could further expand such a network of learning.

Besides, community people have a firm faith that the body of knowledge can make their life better without migrating to work elsewhere. They can work from home and still physically remain with their families. Moreover, community people are generally kind and hospitable and they do not monopolize their knowledge and expertise. This can also be witnessed from their willingness to share their knowledge and skills with those who are interested in the craft and eager to learn from them in the belief that the transfer of knowledge and skills can maintain their tradition of pottery making for the next generation. Likewise, people in the community have love and faith in the body of knowledge without thinking of becoming rich. Though they are still poor and the job is difficult, they will continue making pottery because they gain happiness from their job. They also think that it is a source of their small income that makes them happy together in the family.

\section{Community Environment}

This refers to the environment that supports and encourages learning and which consists of knowledge and learning resources for the community.

The key knowledge of the community is that of clays and pottery making, which is an asset available in the community. Originally, knowledge of pottery making was considered essential to the common interest of the community in that it could benefit their community, thus the reason why they were eager to learn and apply such knowledge. Traditional knowledge of pottery making was passed on by the native Kha tribe who made their household accessories by manual labor. Their products were simple, large, and without complexities of designs or models.

In a later stage, there were developments in pottery by opening up to new knowledge, techniques, and skills from external academics, experts, and art designers. This led to new and exotic patterns of pottery products, not only intended for household use, but also for home and garden decorations. The newly-created patterns were more delicate and complex and sometimes decorated with paintings on them. During this period, there was a mix of traditional and modern knowledge, resulting in pottery products that reflected old and new wisdom.

Recently, there have been advancements of knowledge through applications of traditional and modern knowledge for commercializing the products on a wider scale. Moreover, community leaders understood the situation and put in efforts for more acceptance of the community products by encouraging favorable learning atmosphere, both in and outside the community, in accordance with the notion of a learning organization. Marquardt (1996), in describing such an organization, clearly explains that people learn and are ready to transfer their 
knowledge depending on whether the atmosphere is conducive or not. Community leadership plays an active part in exporting the pottery products to several countries. Furthermore, the traditional lifestyle of people in the community is quite encouraging for members to participate in learning activities. The presence of shops, factories, and kilns is another encouraging factor that opens the community to continuous learning, leading to a higher level of learning atmosphere in which everyone in the community can learn and exchange ideas anywhere and anytime until it becomes their tacit knowledge of Dan Kwien pottery village.

As for learning resources, this study found that Dan Kwien community was full of learning resources learned individuals, natural resources, factories, kilns, jar houses, and shops. These resources are scattered in the community and open to public learning, especially learned individuals; i.e., traditional teachers who are ever willing to transfer their existing knowledge to younger generations. Moreover, Dan Kwien Municipality arranged a learning center equipped with VDO and multimedia presentation for interested public, including a traditional knowledge course for youths to learn from their teachers, experts, specialists, community leaders, and experienced people in the community.

\section{Learning Process and Transfer of Knowledge}

Based on the study, it was found that the community learning process began with learning and apprenticeship under the supervision of Kha elders, considered outsiders at that time, and then passed on to family members from one generation to another. At the same time, outside buyers came in and exchanged their ideas with the community, leading to an initial learning community that later on expanded the learning base by not focusing on just family members, but working side by side with other people in their community. More interest in learning the art of pottery making followed because they realized the potential and benefits of the pottery business. During this period, each family was filled with a good atmosphere for pottery making as they could learn from their parents and relatives. They also passed on their knowledge and skills to their close assistants, called "Looksit" (students). Moreover, community people could interact and learn from outside academics, experts, and specialists who arrived and stayed in the community for some time, resulting in new models and designs of their products.

In the period of developing technical knowledge for commercializing products, the community learning process was not restricted to family affairs, but expanded to learning from outsiders, such as teachers of traditional knowledge courses, at both primary and secondary levels, invited training experts, and community leaders who arranged several activities conducive to learning. In addition, they learned from study tours, seminars, and meetings among themselves or their family representatives and with other groups of people outside their community. They also learned about the production and work process; i.e., the observation that they could sell more products with acceptance and recognition from their customers when they set up shops and factories with their own kilns. In their factory, community people and those from other villages were working together, paving the way for exchanging and transferring their skills and knowledge among themselves and to their children and grandchildren who had the chance to see and absorb what their parents and elder people were doing, which, in turn, helped them carry on the traditional knowledge and wisdom of the community.

During this period, learning had widened extensively with community people opening themselves up to new knowledge and techniques from available mass media, local relays of news and information, useful customer suggestions, and problem-based learning. Thus, it can be seen that the community learning process continued actively and progressively to suit the changing needs of society, focusing mainly on satisfying their customers' demand for the products. With the appropriately combined applications of traditional and modern knowledge of pottery making, Dan Kwien pottery has its own unique identity that has been well recognized worldwide.

\section{CONCLUSION AND DISCUSSION}

In conclusion, Dan Kwien subdistrict possesses the characteristics of a learning community within the research framework; i.e., people in this community have various ways of learning to make themselves specialized or skillful. The learning community started with two groups of people - natives and Kha tribal people, who share their learning experience of pottery making using natural clays available in the community as a common learning object. 
With the passage of time, pottery making has grown from domestically used items to commercial commodities. The growth is the direct result of thinking and learning processes of community people, which further nurtures awareness and love of wisdom among local people who also aim to preserve and extend community knowledge.

Besides, learning characteristics are in the form of knowledge transfer in the workplace under the supervision of the pottery master through knowledge sharing and cooperative work. This type of knowledge transfer plays a major role in team learning of Dan Kwien community, which is different from business enterprises in the sense that learners do not have prior knowledge of pottery making. They are only interested in learning, and thus take part in apprenticeship or team up with other workers. The team learning at Dan Kwien primarily consists of pottery masters, wisdom or traditional academic teachers. So, anyone interested in the art of pottery making can just walk in and enroll themselves as students under the care of the masters or teachers. The most important incentive for them is income to support themselves and their families. Consequently, they learn how to make pottery through repeated actions and several reproductions to the point that it becomes their personal mastery, which ultimately yields the end results comparable to Senge's framework (1990).

Learning atmosphere in the community is different from classroom learning. This learning process takes place in the pottery factory itself (called 'Rong Hai' in Thai or 'Jar House' in English), equipped with everything available in the community. Therefore, people participated in such learning process and atmosphere since childhood through direct experience, observation, and assimilation, making them think more creatively, understand the process of pottery making clearly, and able to make their own masterpieces and products through their conviction practice and reproductions finally leading to their personal mastery. At the same time, they developed and tremendously increased their capabilities and skills in pottery production through learning atmosphere similar to that of Marquardt (1996) who describes it as learning atmosphere resulting from the community structure itself. Dank Kwien environment, consisting of pottery knowledge, natural resources, and learning resources, significantly contributes to learning, transfer of knowledge, and applications of knowledge in their occupation.

Noticeably, system thinking, with regard to pottery making, has made community people open themselves up for new knowledge and skills from both inside and outside, in order to further extend their traditional knowledge and wisdom, leading to new designs and styles of products by mixing old and new paradigms.

However, to make community-based learning possible, community leaders play a major role in accelerating the learning process and creating a shared vision that gives clear directions of progress, not confined to any householders, in particular, but coming from their joint efforts in producing and responding to the market needs simultaneously. At Dan Kwien community, formal leaders play an important part in developing the community, especially the Mayor of Dan Kwien sub-district who is also a native and close to local people. He will listen and talk to the people. Before arranging activities, he will invite pottery household representatives to a meeting for idea and experience sharing with each other. From this point onward, team learning starts to materialize, with the help from coaches and mentors who guide and moderate their workshop, organize tours outside their community, hold pottery fairs in the community, and invite academics from outside to give training on various aspects of learning, with the purpose of learning, exchange and transfer of knowledge, and applying their knowledge in their occupation to earn income for themselves and their family.

Besides, informal leaders, who are also traditional wisdom teachers, serve as important learning sources that motivate people in their community to learn, transfer knowledge, exchange ideas, and apply knowledge in their occupation. Traditional wisdom teachers are divided into two categories - traditional potters and academics. These teachers are willing and available to give advice and answer questions. They are well-respected by community people, and the community people know who specializes in what. The two types of teachers make a balanced combination of old and new knowledge and wisdom.

Furthermore, there is a continuous transfer of knowledge within the family and from one generation to another, creating a common bond and awareness among community people and also generating income for them without having to work outside their community. The transfer of knowledge also takes place between community people and outsiders, focusing on action learning in which learning processes were made through interaction in 
different situations, such as meeting, field study, exporting, etc. This implied Marquand's principle of learning organization (Marquard, 1996).

Based on the results of the study, it can be concluded that formal concepts and theories of a learning organization, such as those of Senge (1990), can be applied to explain the characteristics of Dan Kwien learning community. However, the differences are that in a formal organization, employees are recruited or hired on the basis of their knowledge and ability, get on-the-job training, apply their knowledge and skills for the job at hand, and think and solve problems in a systematic manner. For a learning community, people need to see the benefits for themselves and their families first, after which they will take interest in learning and training together with - or from

- others. This learning method of re-enforcement and reproduction makes them become, more or less, experts or specialists which ultimately can be utilized to benefit and add value to their community.

It is noted that characteristics of the community people, who have undergone this type of learning process, are the same as those in a learning organization in accordance with Senge (1990). On the part of leadership development, when people in the community are able to create their own expertise and further develop their existing knowledge up to the point where they can produce new products or can develop the quality of their products, they will certainly enhance their thinking potential by opening themselves up to new technology, knowledge, and skills from outside in order to extend their knowledge for new products. At the same time, these community leaders are the ones who create and sustain the vision and set directions for the community. They are also the key players in coaching, providing information, and arranging various activities to promote learning, exchanging ideas, and transferring knowledge for developing product quality and imprinting knowledge deep into the minds of people. All these serve as a learning process that activates the community into a learning community. Thus, it can be concluded that the concept of a learning organization is applicable to the study of a social organization as well.

\section{RECOMMENDATIONS}

1. Dan Kwien community should be further supported in order to create a total learning atmosphere. Currently, Dan Kwien community consists of shops and factories. Even under their houses, there are small factories and sales stalls. When people walk into the area, they can see various different designs of pottery, shop decorations, and road signs showing the Dan Kwien identity where everyone can freely learn by themselves. They can also learn from watching the molding process and directly from the potters. So, government units responsible for Dan Kwien community development should apply this concept in developing Dan Kwien as an independent learning atmosphere where everyone who walks in can observe and learn freely from ways of people's livese in the community.

2. Common interest is the key factor for development. So to determine approaches to development, it is imperative to analyze the context and search for existing knowledge and strengths that people take common interest in and benefit from. However, common interest should have concrete impact on individuals as well as community. In Dan Kwien, the focus is pottery.

3. Building leadership is necessary as it is the major factor that guides and controls community development. Good leaders should have a strong sense of love for the community, be aware of the significance of folk wisdom, and be keen on extending or redefining such wisdom as their permanent community heritage.

There are two kinds of leadership in Dan Kwien community - formal, such as Mayor and his staff, and informal or natural, such as people interested in making and developing pottery products, not only for themselves, but also for their own community as well. Formal leaders should be open-minded and be both knowledge leaders and knowledge workers in the community.

4. In developing a learning community, there should be mechanisms that help create a conducive atmosphere for team learning, stressing love of - and faith in - community knowledge and wisdom. Leaders should push for better understanding of people in the community. Based on this research, community structure has impacts on the development of a learning community. For example, people with their family name ending with "Kratok" will have more unity and hospitality toward each other, like in a flat organization, which is most suitable for common learning. This research also found that community learning is usually informal, the result of real practices with guidance and help from the master. Through repeated practices and reproductions, they gain the mastery. 
Therefore, the creation of mechanisms for common community learning may have to be processed through practical activities, rather than formal classroom learning, in a form of group learning which also generates benefits; for instance, Textile Weaving Group or Pottery-making Group. Mechanisms can likewise be formed through networking, such as Network of Experts who will discuss, exchange ideas, and plan together for a common learning of people in the community.

\section{AUTHOR INFORMATION}

Suchada Namjaidee, Ph.D. Candidate, Liberal Arts, Development Science, Faculty of Humanities and Social Sciences, Khon Kaen University.

Lampang Manmart, Associate Professor, Information and Communication Management Program, Faculty of Humanities and Social Sciences, Khon Kaen University.

Yaowalak Apichatwallop, Assistant Professor, Social Sciences Program, Faculty of Humanities and Social Sciences, Khon Kaen University.

Peerasit Kamnuansilpa, Associate Professor, College of Local Administration, Khon Kaen University.

\section{REFERENCES}

1. Bordin Wijarn. (2004). Knowledge Management to Wisdom Practice. Bangkok: Expernet.

2. Center for Academic Assistance in Community Development Region 11 Nakhon Ratchasima. (n.d.). Database of Knowledge - based Village Cluster Chokchai Nakhon Ratchasima Province. Nakhon Ratchasima: Center for Academic Assistance in Community Development Region 11 Nakhon Ratchasima.

3. Center for Academic Assistance in Community Development Region 11 Nakhon Ratchasima. (n.d.). DanKwien Pottery Isan Local Wisdom. Nakhon Ratchasima: Center for Academic Assistance in Community Development Region 11 Nakhon Ratchasima.

4. Jirawat Weerangkorn. (2005). Trends in Students' Development for Reinforcing Thai Graduates' Characteristics in International Communities. Retrieved on August 14, 2005, from http://newgrad. sa.ku.ac.th/index.php?option=com ontent\&task=view\&id=www.neepandin.com/data/society/4b.htm=77.

5. $\quad$ Marquardt, M. (1996). Building the Learning Organization. New York: McGraw-Hill.

6. Office of National Economic Development Commission, Office of the Prime Minister. (1997). The National Social and Economic Development Plan 8 (2540-2544 B.E.). Bangkok: The Office.

$7 . \quad$ (2002). The National Social and Economic Development Plan 9 (2545-2549 B.E.). Bangkok: The Office.

8. __ (2002). The National Social and Economic Development Plan 10 (2550-2554 B.E.). Bangkok: the Office.

9. Office of the Secretary, National Commission on Information Technology. (2002). Thailand Policy Framework of Information Technology Period 2544-2553 B.E. Bangkok: The Office.

10. Parichart Walaisathien, et al. (2003). Developers' Working Process and Techniques. Bangkok. Project on Reinforcement of Learning for Happy Community.

11. Phra Maha Sutit Apakaro. (Oboon). (2005). Innovations in Learning about Man, Community and Development. Bangkok: Pisit Thai Offset.

12. Prong Chaopraya. (2005). Webeducation. Retrieved on September 16,2005, from http:/www.neepandin.com/ data/society/4b.htm

13. Senge, P. M. (1990). The Fifth Discipline: The Art and Practice of the Learning Organization. London: Random House.

14. Seri Pongpit. (2005). Thinking Villages: A Vision for Development. Bangkok: Jaroenwit Publishing.

15. Supatra Chatbunchachai. (n.d.). Learning Process: Concepts, Meaning, and Lessons in Thai Society. Bangkok: Pisit Thai Offset.

16. The Royal Institute. (2002). The Royal Institute Dictionary B.E. 2452. Bangkok: Nanmee Books. 
NOTES 